\title{
$\square$ Reduction of severe functional mitral regurgitation using the percutaneous approach with the Mitraclip system: report on the first Slovenian cases
}

\section{Jana Ambrožič ${ }^{\star}$ \\ Mojca Bervar Matjaž Bunc}

University Medical Centre Ljubljana, Ljubljana, Slovenia
RECEIVED:

April 14, 2015

ACCEPTED:

April 20, 2015
KEYWORDS: mitral valve, mitral regurgitation, mitral repair, Mitraclip, dilated cardiomyopathy. CITATION: Cardiol Croat. 2015;10(3-4):69. | DOI: http://dx.doi.org/10.15836/ccar.2015.69

ORCID: Jana Ambrožič, http://orcid.org/0000-0003-4864-7244 • Mojca Bervar, http://orcid.org/0000-0002-1313-8928 • Matjaž Bunc, http://orcid.org/0000-0001-7269-8944

*ADDRESS FOR CORRESPONDENCE: Jana Ambrožič, Department of Cardiology, University Medical Centre Ljubljana, Zaloška 7, 1000 Ljubljana, Slovenia. Phone: +38615223125. E-mail: jana.ambrozic@gmail.com

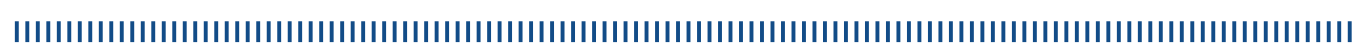

BACKGROUND: Surgical mitral valve repair is considered the gold standard treatment for severe symptomatic valvular mitral regurgitation (MR)1. However, almost half of the patients are not referred for surgery due to increased operative risk related to advanced age and co-morbidities ${ }^{2}$. On the other hand in patients with severe functional MR due to ischemic or non-ischemic dilated cardiomyopathy the results of surgery are not favorable and procedural risk is much higher. The percutaneous mitral valve repair with the Mitraclip system has emerged as an alternative option for high-risk inoperable patients and as an adjunctive heart failure therapy for patients with advanced cardiomyopathy ${ }^{3}$. Transesophageal echocardiography plays a pivotal role in the assessment of specific and restrictive anatomical criteria that need to be fulfilled for the Mitraclip procedure. In addition it is used as the primary imaging modality to guide the procedure. We report the first Slovenian Mitraclip cases and their 3-month outcome.

CASE REPORTS: Three symptomatic patients with ischemic dilated cardiomyopathy and severe ischemic functional MR were selected for the Mitraclip therapy. Two of them had previous cardiac bypass surgery and percutaneous coronary interventions and one patient had suffered extensive anterior myocardial infarction. They were symptomatic (functional class NYHA III or IV) despite optimal medical therapy with no option for revascularization. One patient was also non-responder to cardiac resynchronization therapy. Echocardiography before the procedure confirmed suitable anatomical conditions. Mitraclip therapy was feasible in all patients. During follow-up of 3 months functional class improved, mild residual MR remained stable and reduced left ventricle volumes were detected.

CONCLUSIONS: First Slovenian experience with the Mitraclip therapy confirmed feasibility of the procedure and demonstrated improved functional class and reverse left ventricular remodeling in our patients. Careful assessment of the mitral valve anatomy with comprehensive echocardiography is crucial in this procedure.

LITERATURE IIIIIIIIIIIIIIIIIIIIIIIIIIIIIIIIIIIIIIIIIIIIIIIIIIIIIIIIIIIIIIIIIIIIIIIIIIIIIIIIIIIIIIIIIIIIIIIIIIIIIIIII

1. Joint Task Force on the Management of Valvular Heart Disease of the European Society of Cardiology (ESC); European Association for Cardio-Thoracic Surgery (EACTS),Vahanian A, Alfieri 0, Andreotti F, Antunes MJ, Barón-Esquivias G, Baumgartner H, et al. Guidelines on the management of valvular heart disease (version 2012). Eur Heart J. 2012;33:2451-96. DOI: http://dx.doi.org/10.1093/eurheartj/ehs109

2. Mirabel M, lung B, Baron G, Messika-Zeitoun D, Détaint D, Vanoverschelde JL, et al. What are the characteristics of patients with severe, symptomatic, mitral regurgitation who are denied surgery? Eur Heart J.2007;28:1358-65. DOI: http://dx.doi.org/10.1093/eurheartj/ehm001

3. Beigel R, Wunderlich NC, Kar S, Siegel RJ. The evolution of percutaneous mitral valve repair therapy: lessons learned and implications for patient selection. J Am Coll Cardiol. 2014;64:2688-700. DOI: http://dx.doi.org/10.1016/j.jacc.2014.08.049 